\title{
Crystallographic Investigations of Biotin and Carboxybiotin Derivatives ${ }^{a}$
}

\author{
WILLIAM STALLINGS \\ Biophysics Research Division \\ The University of Michigan \\ 2200 Bonisteel Boulevard \\ Ann Arbor, Michigan 48109 \\ GEORGE T. DETITTA \\ Molecular Biophysics Department \\ Medical Foundation of Buffalo \\ 73 High Street \\ Buffalo, New York 14203
}

A substantial number of biotin and carboxybiotin derivatives have been investigated crystallographically over the last ten years in an effort to define three-dimensional parameters that may be important in biotin catalysis. We have elected to review this work, not in a structure-by-structure fashion, but in a manner that will underline the relevance of the structures to the two half-reactions which characterize biotinmediated carboxyl transfer and the possible translocation events which may separate them. Our analysis will point to the importance of studying both the intra- and the intermolecular interactions in these structures. The high resolution structure of (+)-biotin at $125^{\circ} \mathrm{K}$ is described and the structure of $\mathrm{Nl}^{\prime}$ methoxycarbonyl biotinyl acetate is also reported. We have re-examined the structure of $\mathrm{N} 1^{\prime}$ methoxycarbonyl biotin methyl ester with results that suggest a structural basis for the observed stereospecificity of the second half-reaction.

\section{HIGH RESOLUTION STRUCTURE OF BIOTIN AT $125^{\circ}$ KELVIN}

Crystallography and biotin are no strangers. In 1942, shortly after du Vigneaud, Hofmann, Melville and Gyorgy ${ }^{\prime}$ reported the isolation of vitamin $\mathrm{H}$ in crystalline form, Fankuchen ${ }^{2}$ published a short note describing the crystal optical properties and cell constants of the coenzyme. From this information he suggested that biotin is "... a flattish molecule lying approximately in the $b c$ plane." Admittedly, this was a low resolution study by today's standards (as Fankuchen put it, ". . . indeed only the great interest in biotin could warrant its publication in its present form.") but it marked the beginning of the attention that crystallographers have devoted to the biotin molecule. Some 14 years passed before Traub ${ }^{3}$ in 1956 confirmed Fankuchen's predictions, determining the two-dimensional structure of biotin in the $b c$ plane. Thus the bicyclic moiety of the vitamin was shown to be boat-shaped, with the sulfur atom up out of the tetrahydrothiophene plane, the ureido plane flat, and the ring-chain junction twisted to form an elongated molecule. This work was followed by that of Bonnemere, Hamilton,

\footnotetext{
${ }^{a}$ This work was supported by Grants AM1 9856 and CA10925 from the National Institutes of Health.
} 
Steinrauf, and Knappe, ${ }^{4}$ who in 1965 reported the three-dimensional structure of the bis-para-bromoanilide of carboxybiotin and established that the site of $\mathrm{CO}_{2}$ fixation was $\mathrm{Nl}^{\prime}$; the absolute configuration of the cofactor was later determined crystallographically from these data. ${ }^{5}$ Ten years later crystallographic work was again resumed, in fact by two independent laboratories, and the three-dimensional structure of biotin itself was finally determined by DeTitta, Edmonds, Stallings, and Donohue ${ }^{6}$ in 1976. The results of our two studies detailed the overall geometry of the molecule, especially the delocalized nature of the bonding in the ureido $\mathrm{C}=\mathrm{O}$ and $\mathrm{C}-\mathrm{N}$ bonds, and the presence of a strong hydrogen bond to the ureido oxygen, suggestive of the type of complex that might be found in the active site of a biotin-dependent enzyme leading to activation towards $\mathrm{CO}_{2}$ attack. ${ }^{7}$

Recently, we have gone back to the biotin problem in the hope of examining the details of the electronic structure of the vitamin. It is necessary to keep in mind that the $\mathrm{X}$-ray diffraction experiment is a direct probe of the electron density, $\rho(r)$, of a molecule in a crystal lattice; that is, $\mathrm{X}$-rays interact with electrons strongly and with nuclei very weakly. With this in mind we have conducted two high resolution experiments, one in Ottawa at the National Research Council, at $125^{\circ} \mathrm{K}$ to $1.0 \AA^{-1}$ (sin $\theta / \lambda ; \lambda=0.7107 \AA$ ). Over 40,000 diffraction spectra were recorded and processed to yield some 5200 unique reflection values. (In comparison, Fankuchen measured a handful of the strongest reflections, Traub visually estimated about $70 \%$ of the reflections recorded in Weissenberg photographs for the hkl levels $h=0$ to 3 and $k=0$ to 7, while in our three-dimensional studies we measured data to a resolution of $\sim 0.6$ $\AA^{-1}$ yielding some 1100 unique reflections.) From an optical viewpoint the high resolution data allow peaks in a Fourier map separated by no less than $\sim 0.3 \AA$ to be clearly resolved; this is the resolution we need to examine the bonding density between nuclei. The diffraction data were recorded at $125^{\circ} \mathrm{K}$ to reduce the thermal motion of the atoms and thereby enhance the high angle scattering.

As of now the data have been employed in a standard least-squares refinement using spherical atom form factors; positional and harmonic anisotropic thermal parameters were refined to a standard crystallographic $R$ value of 0.041 for all data $(R=0.035$ for the 4700 reflections with $I>2 \sigma)$. The average precision in a bond length between non-hydrogen atoms is $0.001 \AA, 0.01 \AA$ in $\mathrm{C}-\mathrm{H}, \mathrm{N}-\mathrm{H}$ and $\mathrm{O}-\mathrm{H}$ bonds; bond angles are determined to $0.1^{\circ}$ between non-hydrogen atoms, angles of the type $\mathrm{C}-\mathrm{C}-\mathrm{H}$, etc., to $0.5^{\circ}$; torsion angles are determined to $0.1^{\circ}$ in sequences of the type $\mathrm{C}-\mathrm{C}-\mathrm{C}-\mathrm{C}, 1.2^{\circ}$ in sequences of the type $\mathrm{C}-\mathrm{C}-\mathrm{C}-\mathrm{H}$. Torsion angles of the form $\mathrm{H}-\mathrm{C}-\mathrm{C}-\mathrm{H}$, important in the analysis of NMR coupling constants (see below), are determined with a precision of $1.3^{\circ}$. Selected bond distances and angles are given in FIGURE 1, which also indicates the labeling of atoms that we shall use throughout our discussion.

What is reassuring is that there are no major changes in the observed bond distances, angles, or torsion angles in the high resolution refinements versus our earlier moderate resolution refinements. The $\mathrm{C}=\mathrm{O}$ bond in the ureido group is still observed to be long $(1.249 \AA)$, the ureido carbonyl $\mathrm{C}-\mathrm{N}$ bonds short $(1.349,1.351 \AA)$ and the ureido ring planar, indicative of the extensive delocalization of the carbonyl double bond density into the $\mathrm{C}-\mathrm{N}$ bonds. The asymmetry of the tetrahydrothiophene ring, only barely significant in our earlier refinement, is now clearly observed; the $\mathrm{S}-\mathrm{C} 2$ $(1.824 \AA)$ and $S-C 5(1.815 \AA)$ bond distances differ by more than $6 \sigma \Delta$, and similarly, the $\mathrm{C} 2-\mathrm{C} 3(1.543 \AA)$ and $\mathrm{C} 5-\mathrm{C} 4(1.537 \AA)$ distances differ by more than $6 \sigma \Delta$. In contrast, the equivalent bond distances in the ureido ring differ by no more than $1.5 \sigma \Delta$. Clearly the valeryl chain at $\mathrm{C} 2$ disturbs what would be perfect bilateral symmetry in the bicyclic moiety. The ureido oxygen accepts the strong hydrogen bond from a neighboring carboxylic acid $\mathrm{OH}$ group $(\mathrm{O}$. . O distance $2.545 \AA$ ). 
While our analysis of the bonding density in biotin is clearly at a preliminary stage, there are some results which are of interest with regard to the ureido group. The electron density in the $\mathrm{C}=\mathrm{O}$ bond is polarized towards the carbon atom while the lone pair elecirons on the oxygen are clearly discernible. The bonding density in the carbonyl carbon-nitrogen bonds extends normal to the ureido plane and is ellipsoidally shaped in comparison to the $\mathrm{Nl}^{\prime}-\mathrm{C} 4$ and $\mathrm{N} 3^{\prime}-\mathrm{C} 3$ bonds which are more nearly spherically symmetric. All these effects are consistent with the notion of a delocalized

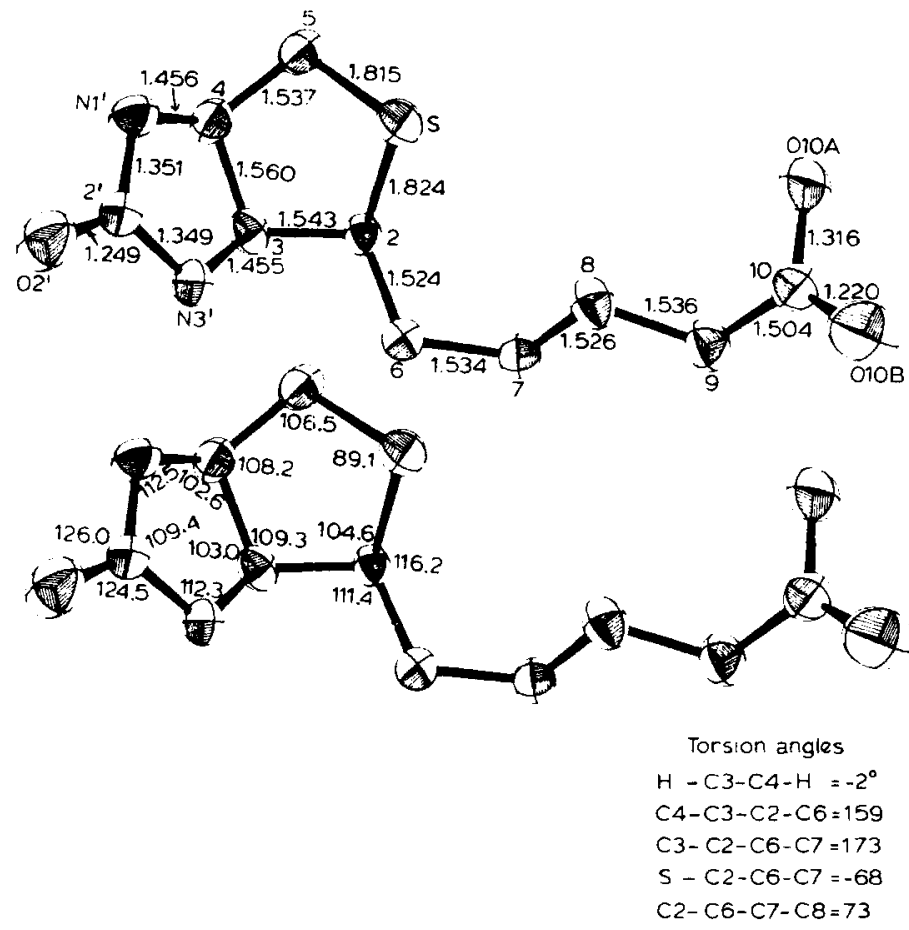

FIGURE 1. Bond lengths $(A)$ and bond angles ( ) determined for $(+)$-biotin at $125^{\circ} \mathrm{K}$. The precision of the values is discussed in the text. The labeling of the atoms that will be used throughout our discussion is also indicated in this figure.

$\pi$ system of electrons in the ureido moiety as suggested by the bond lengths. Further work will be directed towards an analysis of the electron density about the sulfur atom as well as a full mapping of the electrostatic potential in the ureido group.

\section{THE STRUCTURES OF BIOTIN DERIVATIVES AND THEIR RELEVANCE TO THE FIRST HALF-REACTION}

In this section we focus on the molecular and electronic structure of the ureido moiety of the uncarboxylated coenzyme and some of its derivatives for which X-ray structures exist. The room temperature structure of $(+)$-biotin ${ }^{6}$ illustrates that the 
ureido portion of the biotin is polarized with substantial contributions from the urea-like, charge-separated resonance forms of the coenzyme:

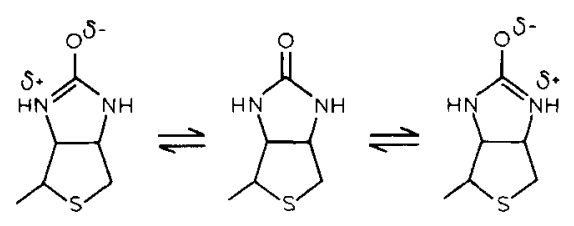

The $\mathrm{C} 2^{\prime}=\mathrm{O} 2^{\prime}$ bond at $1.25 \AA$ and the $\mathrm{C} 2^{\prime}-\mathrm{N}^{\prime}$ and $\mathrm{C} 2^{\prime}-\mathrm{N} 3^{\prime}$ bonds at 1.33 and 1.35 $\AA$ are, respectively, longer and shorter than accepted values ${ }^{8}$ for $\mathrm{C}=\mathrm{O}(1.20 \AA)$ and $\mathrm{C}-\mathrm{N}(1.47 \AA)$ bonds; this molecular geometry suggests a partial negative charge localized at the ureido oxygen, $\mathrm{O}^{\prime}$, and a partial positive charge delocalized over the $\mathrm{N} 1^{\prime}-\mathrm{C} 2^{\prime}-\mathrm{N} 3^{\prime}$ bonding network. Investigations of structures of other biotin derivatives, ${ }^{9-11}$ including dethiobiotin, biotin methyl ester, selenobiotin, oxybiotin, azabiotin, carbobiotin, biotin sulfone, and biotin- $d$-sulfoxide, have verified this interpretation of the electronic structure of the ureido moiety of biotin. Further, a negatively sloped plot $^{11}$ of the urea-like $\mathrm{C}=\mathrm{O}$ vs. $\mathrm{C}-\mathrm{N}$ bond lengths in these derivatives has demonstrated the linear interdependence of these parameters and illustrates the electronic fluidity of the ureido region of the biotin molecule; any enhancement of the single bond or enolate character of the ureido carbonyl bond, $\mathrm{C}^{\prime}=\mathrm{O}^{\prime}$, is reflected in enhanced double bond character in the $\mathrm{C}^{\prime}-\mathrm{N1}^{\prime}$ and $\mathrm{C}^{\prime}-\mathrm{N} 3^{\prime}$ single bonds. Blessing ${ }^{12}$ has amply studied this phenomenon and extended it to include urea, urea complexes and the oxygen-protonated uronium ion; his results suggest that the electronic fluidity of the ureido region extends smoothly to the oxygen-protonated form of the biotin cofactor, enol-biotin.

Any mechanism that describes the carboxylation of biotin at N1' must account for its nucleophilic activation. The results reviewed above suggest that the electronic structure of the ureido ring system, already substantially polarized and thereby able to interact with ions and polar molecules, is on a pathway for activation to the enol tautomer. The packing in the crystal structure of $(+)$-biotin (FIG. 2a) reveals in-plane complementary hydrogen bonding between $\mathrm{O}^{\prime}$ and $\mathrm{N1}^{\prime}-\mathrm{H}$ of the ureido moiety of the molecule and the protonated carboxyl side chain of a neighboring molecule. Related hydrogen bonding schemes are observed in oxybiotin, selenobiotin, biotin sulfone, carbobiotin, ${ }^{11}$ dethiobiotin, ${ }^{9}$ and some urea-acid complexes. ${ }^{13,14}$ These structures have provided two useful three-dimensional models for nucleophilic activation at N1'. Figure $2 \mathrm{~b}$ illustrates a previously proposed mechanism ${ }^{7}$ in which cofactor recognition of the bicarbonate substrate is by complementary hydrogen bonding; generation of the enol tautomer results from proton transfers across the hydrogen bonds involved in this recognition. FIGURE $2 c$ envisions a similar event in which the activation occurs via interaction with a carboxylic residue from the protein. In both cases the proton transfers result simply in an exchange of the donor and acceptor hydrogen bonding roles.

\section{TRANSLOCATION MECHANISMS}

The requirement of separate sites on a biotin-dependent enzyme for attachment of $\mathrm{CO}_{2}$ and for its transfer has led to speculation on how biotin gets from one site to the 
other. Acknowledging that biotin is invariably amide-linked through its carboxylate group to the amino nitrogen of a lysine residue, a number of investigators have envisioned a swinging arm mechanism whereby $\mathrm{Nl}^{\prime}$-carboxybiotin might swing as much as $20-30 \AA$ from one site to the other. Nevertheless, evidence that the sites of carboxylation and decarboxylation might be as close as $7 \AA$ in transcarboxylase from $P$. shermanii has come from a combination of spectral techniques. ${ }^{15-17}$ We wish to discuss translocation scenarios consistent with the $7 \AA$ separation between active sites.

The mechanisms were suggested by the bicyclic ring-valeryl chain junction geometries observed in biotin, dethiobiotin, azabiotin, and six other biotin vitamers. ${ }^{6,9-11}$ While translocation of the biotin bicyclic moiety could be effected by one or more rotations about any or all of the $10 \mathrm{C}-\mathrm{C}$ single bonds in the lysylvaleryl chain, translocation of the carbon dioxide carbon atom (bound at $\mathrm{N}^{\prime}$ ) can be managed by rotations about the $\mathrm{C} 2-\mathrm{C} 6$ and/or $\mathrm{C} 6-\mathrm{C} 7$ bonds alone. We need invoke no unlikely geometries for the ring-chain junctions; indeed all the geometries are ones observed in our diffraction studies. As an example we take the case of a translocation consistent with the observed conformations of biotin and its sulfone (FIG. 3). In biotin the conformation about the $\mathrm{C} 2-\mathrm{C} 6$ bond is - gauche (torsion angle $\mathrm{S}-\mathrm{C} 2-\mathrm{C} 6-\mathrm{C} 7$

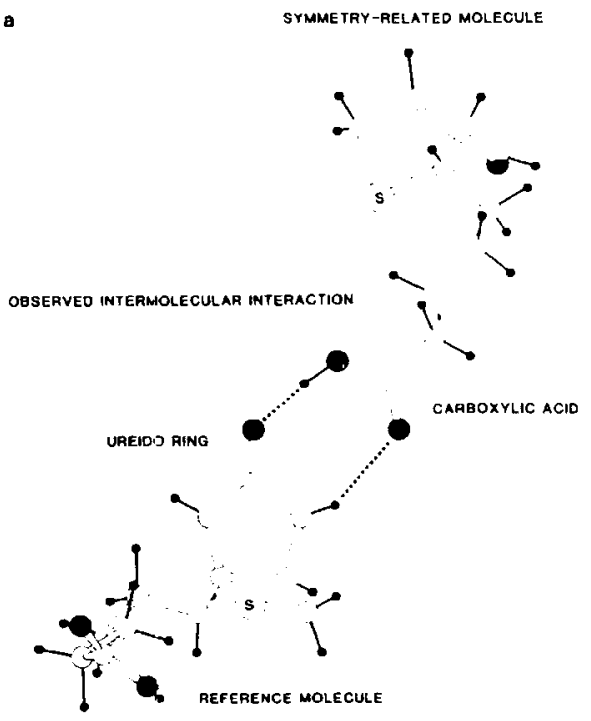

FIGURE 2. (a) Intermolecular interaction observed in the structure of $(+)$-biotin between the ureido group of one molecule and the protonated carboxyl group of the valeryl side chain of a symmetry-related, neighboring molecule. The interaction involves complementary, in-plane hydrogen bonding in which $\mathrm{N1}^{\prime}-\mathrm{H}$ and $02^{\prime}$, respectively, of the ureido moiety play donor and acceptor roles. The interaction suggests related mechanistic schemes by which nucleophilic activation of the biotin cofactor might occur. (b) Scheme I, substrate recognition and activation. Recognition of the substrate, bicarbonate, is by complementary hydrogen bonding. Proton transfers across the hydrogen bonds, result in reversal of the donor-acceptor roles and the generation of enol-biotin. (c) Scheme III, enzyme activation. The ureido portion of the cofactor hydrogen bonds to a protonated carboxylic acid residue of the protein. Similar proton transfers across the hydrogen bonds generate enol-biotin. 

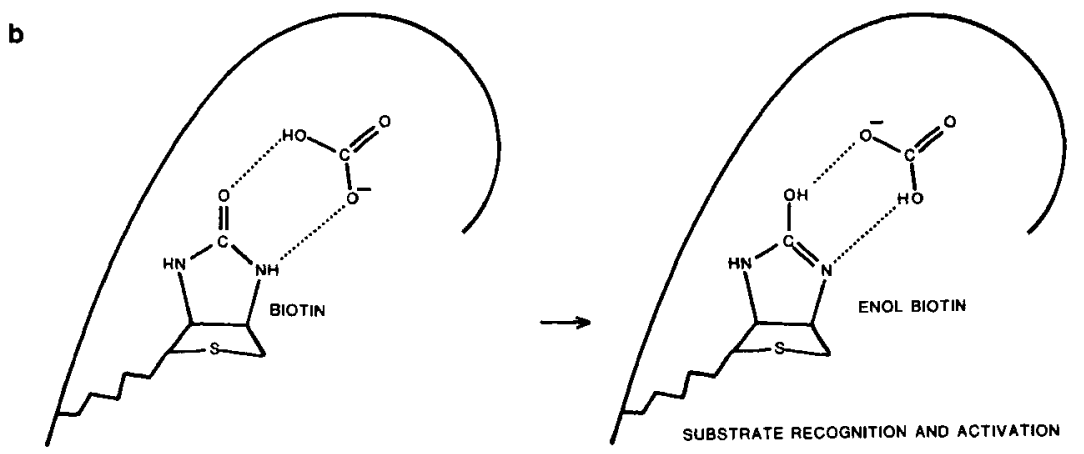

ENZYME ENZYME

$\mathbf{c}$

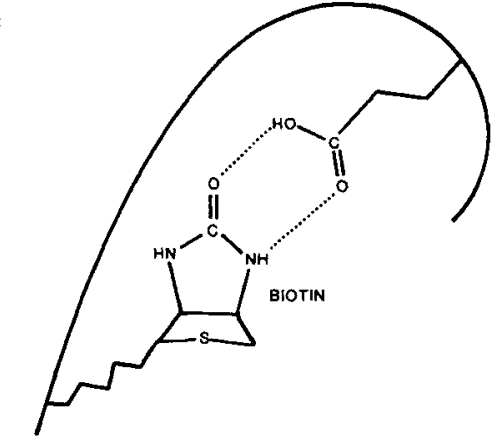

ENZYME

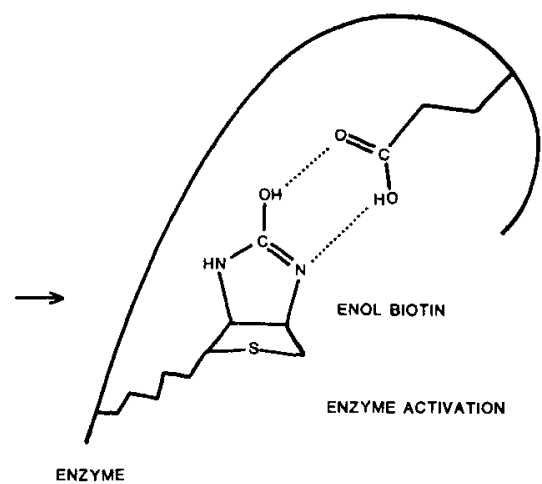

FIGURE 2. (Continued).

$\sim-60^{\circ}$ ); in biotin sulfone it is trans $\left(\sim 180^{\circ}\right)$. About the $\mathrm{C} 6-\mathrm{C} 7$ bond (torsion angle $\mathrm{C} 2-\mathrm{C} 6-\mathrm{C} 7-\mathrm{C} 8)$ the biotin geometry is + gauche $\left(\sim+60^{\circ}\right)$; in its sulfone it is trans. If the carbon atoms $\mathrm{C} 7$ through $\mathrm{C} 10$ of the valeryl chains are fitted pair-wise, biotin to biotin sulfone, we observe that a $\mathrm{CO}_{2}$ carbon atom bound at $\mathrm{Nl}^{\prime}$ would be displaced 6.9 $\AA$. That is to say, two gauche $\rightarrow$ trans rotations about the $\mathrm{C}-\mathrm{C}$ bonds closest to the bicyclic moiety of $\mathrm{N}^{\prime}$ '-carboxybiotin would effect a $\sim 7 \AA$ translocation. A number of other scenarios" similar to this example, involving only gauche $=$ gauche or gauche $=$ trans rotations about the $\mathrm{C} 2-\mathrm{C} 6$ and/or $\mathrm{C} 6-\mathrm{C} 7$ bonds and only conformations observed in diffraction studies, can be envisioned with translocation distances ranging from $4.4 \AA$ to $6.9 \AA$.

Recently, 2D NMR studies ${ }^{18}$ of biotin were carried out in Japan; their aim was a full assignment of the ${ }^{13} \mathrm{C}$ and ${ }^{1} \mathrm{H}$ resonances in the molecule. The coupling constants between $\mathrm{H}$ atoms bonded to $\mathrm{C} 2$, the ring junction carbon and $\mathrm{C} 6$, the proximal carbon in the valeryl chain, can be analyzed in terms of rapidly interconverting + gauche $=$ trans $=-$ gauche conformers $(88 \%)$ and a possible gauche, -gauche conformation (12\%) not seen in the diffraction studies. The rapid interconversions between $\mathrm{C} 7$ gauche to $\mathrm{S}$ and $\mathrm{C} 7$ trans to $\mathrm{S}$ attest to the modest energy barrier between these conformers.

These translocation mechanisms have a number of appealing features. They 

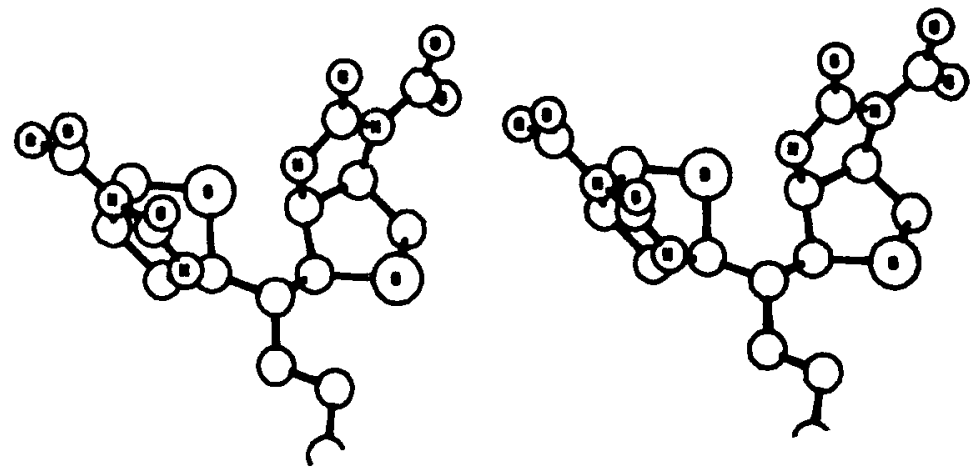

FIGURE 3. One of a number of poss ible translocation scenarios suggested by X-ray structures ${ }^{11}$ and consistent with magnetic resonance studies. ${ }^{19-17}$ The modeling is explained in the text and the diagram is a stereo pair. Illustrated are the conformations observed for biotin and its sulfone. Pairwise fitting of the fully extended ends of the valeryl side chains indicate that conformational motions about the $\mathrm{C} 2-\mathrm{C} 6$ and $\mathrm{C} 6--\mathrm{C} 7$ bonds required to bring the bicyclic ring systems into coincidence would cause a carboxyl carbon bonded to $\mathrm{N}^{\prime}$ to migrate a distance of $6.9 \AA$.

require rotation about at most two, possibly one, $\mathrm{C}-\mathrm{C}$ bond. Moreover, the rotations are themselves energetically efficient, being of the +gauche $=$ trans $\rightleftharpoons-$ gauche type. The modus operandi of the translocation could be an effect local to the bicyclic moiety, such as a change in sulfur coordination or a change in the ureido group hydrogen bonding, rather than a long-range one; the mechanisms leave the amide link between lysine and biotin, very probably hydrogen bonded to the enzyme, unmoved.

\section{STRUCTURES OF N1' CARBOXYBIOTIN DERIVATIVES AND THEIR RELEVANCE TO THE SECOND HALF-REACTION}

The second half-reaction of biotin-mediated catalysis involves transfer of the carboxyl group from the biotin $\mathrm{N} 1^{\prime}$ position to a methyl or methylene group on an acceptor molecule. Interest in the mechanism of this half-reaction has focused on at least two, not unrelated, points: the stereospecificity of the transfer, ${ }^{19-23}$ and the concerted or stepwise nature of the reaction. ${ }^{24-27}$ In our description of the crystal structure of $\mathrm{N}^{\prime}$ ' methoxycarbonyl biotin methyl ester, ${ }^{28}$ we reported an intermolecular interaction between the ureido carbonyl oxygen and a neighboring methyl group which we suggested as a model for an incipient carboxybiotin-substrate interaction. In this section we compare that structure with the structure of a new carboxybiotin derivative, $\mathrm{Nl}$ ' methoxycarbonyl biotinyl acetate, and re-examine the intermolecular interaction in $\mathrm{Nl}^{\prime}$ methoxycarbonyl biotin methyl ester.

\section{Structure Determination of N1' Methoxycarbonyl Biotinyl Acetate}

Crystals of $\mathrm{N}{ }^{\prime}$ methoxycarbonyl biotinyl acetate were obtained from an aqueous methanol solution. Three-dimensional $X$-ray intensity data were collected with an 
automated diffractometer using the $\theta-2 \theta$ scan technique. The intensity data were converted to structure factor amplitudes by application of Lorentz and polarization factors and, an analytical absorption correction was applied; the data were placed on an absolute scale using a Wilson plot. Additional crystal data and details of the data collection are summarized in TABLE 1. The structure, with two molecules in the asymmetric unit, was solved using Patterson-superposition and Fourier techniques. The positions of the sulfur atoms were determined from a Patterson function and used as origin shifts in the eightfold superposition of the sharpened Patterson function; a minimum function revealed the locations of most of the atoms of the bicyclic ring systems. The remaining atoms were located in subsequent Fourier maps, phased initially from the positions of the sulfur atoms and the atoms located in the superposition map. The structure was refined by the method of full-matrix leastsquares. The weights, $w$, for reflections were $\sigma^{-2}(F)$ with weights of zero for reflections below the threshold value. The function minimized in the least-squares calculation was $\Sigma w\left(\left|F_{0}\right|-\left|F_{c}\right|\right)^{2}$. The final crystallographic residuals are $R=0.048$ for all observed data and weighted $R=0.057$; the final $R$ for all data is 0.062 . Final positional parameters are listed in TABLE 2.

All hydrogen atoms were located in intermediate difference Fourier syntheses. After the first cycles of refinement it was noted that atoms $\mathrm{C} 9, \mathrm{Cl0}$ and $\mathrm{O} 10$ of molecule B were involved in irregular molecular geometry. Peaks in difference Fourier maps which would correspond to disordered positions for these atoms were also noted; their occupancy was estimated by occupancy refinement to be approximately $20 \%$. Accordingly, the final refinement included isotropic refinement of the disordered positions for $\mathrm{C} 9 \mathrm{~B}, \mathrm{C10B}$ and $\mathrm{O} 10 \mathrm{~B}$ at $20 \%$ occupancy and anisotropic refinement for the major positions for $\mathrm{C} 9 \mathrm{~B}, \mathrm{ClOB}$ and $\mathrm{O} 10 \mathrm{~B}$ at $80 \%$ occupancy; the remaining non-hydrogen atoms were refined anisotropically. All hydrogen atoms were refined isotropically except those bonded to atoms $\mathrm{C} 7 \mathrm{~B}, \mathrm{C} 8 \mathrm{~B}, \mathrm{C} 9 \mathrm{~B}$ and $\mathrm{C} 10 \mathrm{~B}$ as well as those bonded to $\mathrm{C} 12 \mathrm{~A}$ which are rotationally disordered; these hydrogens were placed at idealized positions with estimated isotropic temperature factors and occupancies. Several points should be addressed regarding the suitability of the model for the observed disorder. The major features of the model involve only atoms $\mathrm{C} 9 \mathrm{~B}, \mathrm{C10B}$ and $\mathrm{O} 10 \mathrm{~B}$; while it is likely that atoms bonded to $\mathrm{C} 9 \mathrm{~B}$ and $\mathrm{C} 10 \mathrm{~B}$ are also to some extent disordered, we could not discern this aspect of the disorder in our data. As a result,

TABLE 1. Crystal Data and Some Details of the Data Collection

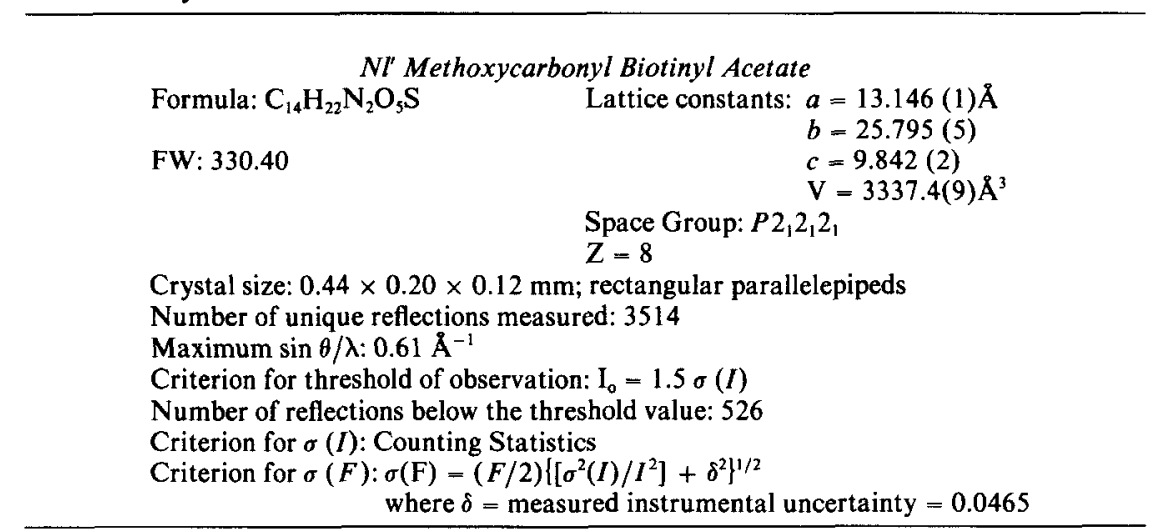


various parameters that define the junction between the ordered and the disordered, low occupancy atoms remain structurally unreasonable $(e . g$., the $\mathrm{C} 7-\mathrm{C} 8-\mathrm{C} 9$ bond angle is $89^{\circ}$ and the $\mathrm{C} 8-\mathrm{C} 9$ bond length is $1.65 \AA$ in the disordered, low occupancy model for molecule B). In this way the model is imperfect; it does, however account for the observed peaks in the difference Fourier maps and is consistent with the $80 \%$ occupancy factors estimated for the major positions of the disordered atoms.

\section{Molecular Structure of NI' Methoxycarbonyl Biotinyl Acetate}

Some geometrical parameters obtained from this structure determination are illustrated in FIGURE 4; the results confirm our previous interpretation ${ }^{28}$ of the substituent effects of the addition of the $\mathrm{N} 1^{\prime}$ methoxycarbonyl group to the uncarboxylated coenzyme. In the structure of $(+)$-biotin ${ }^{6}$ we noted the single bond character of

TABle 2. Positional Parameters for $\mathrm{Nl}^{\prime}$ Methoxycarbonyl Biotinyl Acetate

\begin{tabular}{|c|c|c|c|c|c|c|}
\hline \multirow[b]{2}{*}{ Atom } & \multicolumn{3}{|c|}{ Molecule A } & \multicolumn{3}{|c|}{ Molecule B } \\
\hline & $\underline{\mathbf{x}}$ & $y$ & $\underline{\mathbf{z}}$ & $\underline{\mathbf{x}}$ & $\mathrm{y}$ & $\underline{\mathbf{z}}$ \\
\hline $\mathbf{S}$ & .60205 & .31664 & .7782 & .44107 & .51397 & .1078 \\
\hline $\mathrm{O} 2^{\prime}$ & .3344 & .3995 & .5719 & .5302 & .5000 & .5699 \\
\hline $\mathrm{C} 2^{\prime}$ & .3772 & .3906 & .6783 & .4739 & .5167 & .4827 \\
\hline $\mathrm{Nl}^{\prime}$ & .3566 & .3507 & .7705 & .4819 & .5645 & .4191 \\
\hline N3' & .4552 & .4174 & .7316 & .3914 & .4928 & .4311 \\
\hline $\mathrm{C}$ & .2706 & .3177 & .7593 & .5547 & .6015 & .4533 \\
\hline $\mathrm{O}$ & .2168 & .3146 & .6657 & .6269 & .5942 & .5239 \\
\hline $\mathrm{O}^{\prime}$ & .2630 & .2917 & .8762 & .5337 & .6463 & .3934 \\
\hline$C^{\prime}$ & .1806 & .2541 & .8787 & .6052 & .6873 & .4222 \\
\hline $\mathrm{C} 2$ & .6062 & .3814 & .8525 & .3233 & .4978 & .1945 \\
\hline C3 & .4938 & .3976 & .8583 & .3349 & .5231 & .3359 \\
\hline $\mathrm{C} 4$ & .4268 & .3494 & .8832 & .3998 & .5731 & .3225 \\
\hline $\mathrm{C} 5$ & .4941 & .3012 & .8823 & .4341 & .5780 & .1741 \\
\hline C6 & .6748 & .4177 & .7751 & .3010 & .4402 & .1918 \\
\hline $\mathrm{C7}$ & .6859 & .4703 & .8424 & .2093 & .4242 & .2602 \\
\hline $\mathrm{C} 8$ & .7574 & .5060 & .7685 & .1808 & .3663 & .2386 \\
\hline $\mathrm{C} 9^{a}$ & .7829 & .5548 & .8443 & .1029 & .3425 & .3348 \\
\hline $\mathrm{C} 10^{a}$ & .8540 & .5892 & .7673 & .0059 & .3711 & .3301 \\
\hline $010^{a}$ & .8923 & .6286 & .8565 & -0.0641 & .3532 & .4355 \\
\hline $\mathrm{C} 11$ & .9667 & .6594 & .8060 & -0.1222 & .3119 & .4095 \\
\hline 011 & .9940 & .6565 & .6927 & -0.1270 & .2930 & .2985 \\
\hline $\mathrm{C} 12$ & .9999 & .6979 & .9067 & -0.2008 & .3012 & .5161 \\
\hline HN3' & .505 & .443 & .686 & .355 & .462 & .472 \\
\hline $\mathrm{HC} 2$ & .630 & .376 & .948 & .256 & .518 & .152 \\
\hline $\mathrm{HC} 3$ & .490 & .424 & .934 & .254 & .529 & .391 \\
\hline $\mathrm{HC} 4$ & .396 & .353 & .973 & .360 & .608 & .344 \\
\hline $\mathrm{H} 1 \mathrm{C} 5$ & .517 & .291 & .984 & .382 & .600 & .121 \\
\hline $\mathrm{H} 2 \mathrm{C} 5$ & .466 & .275 & .840 & .504 & .592 & .176 \\
\hline H1C6 & .641 & .421 & .687 & .349 & .423 & .247 \\
\hline $\mathrm{H} 2 \mathrm{C} 6$ & .746 & .397 & .780 & .307 & .431 & .103 \\
\hline $\mathrm{H} 1 \mathrm{C}^{b}$ & .714 & .466 & .938 & .143 & .447 & .220 \\
\hline $\mathrm{H} 2 \mathrm{C} 7^{b}$ & .626 & .482 & .846 & .211 & .431 & .367 \\
\hline $\mathrm{H} 1 \mathrm{CB}^{b}$ & .719 & .519 & .679 & .249 & .345 & .248 \\
\hline $\mathrm{H} 2 \mathrm{C}^{b}$ & .818 & .486 & .752 & .152 & .362 & .138 \\
\hline $\mathrm{H} 1 \mathrm{C} 9^{a, b}$ & .824 & .545 & .937 & .133 & .343 & .436 \\
\hline
\end{tabular}


TABLE 2. Continued

\begin{tabular}{|c|c|c|c|c|c|c|}
\hline \multirow[b]{2}{*}{ Atom } & \multicolumn{3}{|c|}{ Molecule A } & \multicolumn{3}{|c|}{ Molecule B } \\
\hline & $\underline{x}$ & $\mathrm{y}$ & $\underline{z}$ & $\underline{x}$ & $y$ & $\underline{z}$ \\
\hline $\mathrm{H} 2 \mathrm{C}^{a, b}$ & .722 & .573 & .845 & .088 & .304 & .304 \\
\hline $\mathrm{H} 1 \mathrm{Cl} 0^{a, b}$ & .824 & .605 & .688 & -0.023 & .369 & .232 \\
\hline $\mathrm{H} 2 \mathrm{C} 10^{a, b}$ & .918 & .564 & .722 & .027 & .412 & .353 \\
\hline $\mathrm{H} 1 \mathrm{C} 12^{c}$ & 1.059 & .682 & .968 & -0.275 & .323 & .525 \\
\hline $\mathrm{H} 2 \mathrm{C} 12^{r}$ & 1.023 & .732 & .858 & -0.215 & .262 & .545 \\
\hline $\mathrm{H} 3 \mathrm{C} 12^{c}$ & .935 & .707 & .974 & -0.168 & .311 & .595 \\
\hline $\mathrm{H}^{\prime} \mathrm{C}^{\prime}$ & .173 & .248 & .959 & .564 & .718 & .372 \\
\hline $\mathrm{H} 2 \mathrm{C}^{\prime}$ & .094 & .269 & .836 & .603 & .685 & .522 \\
\hline $\mathrm{H}^{3} \mathrm{C}^{\prime}$ & .190 & .224 & .783 & .664 & .681 & .374 \\
\hline \multicolumn{7}{|l|}{$\begin{array}{l}\text { Disordered, } \\
\text { Lower }\end{array}$} \\
\hline Occupancy & \multicolumn{3}{|c|}{ Molecule A } & \multicolumn{3}{|c|}{ Molecule B } \\
\hline Atom & $\underline{x}$ & $y$ & $\underline{z}$ & $\underline{x}$ & $y$ & $\underline{z}$ \\
\hline $\mathrm{C} 9^{d}$ & 一 & - & - & .072 & .374 & .321 \\
\hline $\mathrm{C} 10^{d}$ & - & - & - & .054 & .317 & .382 \\
\hline $010^{d}$ & - & - & - & -0.033 & .316 & .470 \\
\hline $\mathrm{H} 1 \mathrm{C} 12^{e}$ & .975 & .685 & 1.003 & - & - & - \\
\hline $\mathrm{H} 2 \mathrm{C} 12^{\circ}$ & 1.081 & .700 & .901 & - & - & - \\
\hline $\mathrm{H} 3 \mathrm{C} 12^{e}$ & 1.075 & .710 & .878 & - & - & - \\
\hline
\end{tabular}

The estimated standard deviations for the non-disordered carbon, nitrogen and oxygen atoms average; $3 \times 10^{-4}, 1.5 \times 10^{-4}$ and $4 \times 10^{-4}$ for $x, y$ and $z$, respectively. Equivalent values for the sulfur atoms are: $9 \times 10^{-5}, 4 \times 10^{-5}$ and $1 \times 10^{-4}$; for refined hydrogen atoms, these values average: $3.5 \times 10^{-3}, 2 \times 10^{-3}$ and $5 \times 10^{-3}$. For disordered atoms $\mathrm{C}$, $\mathrm{C} 10$ and 010 of Molecule B, equivalent values are $2 \times 10^{-3}, 2 \times 10^{-3}$ and $3 \times 10^{-3}$, respectively.

The occupancy parameter for this atom in molecule B is estimated to be 0.8 .

${ }^{\circ}$ Parameters listed for Molecule $B$ are idealized values included in structure factor calculations and refinements.

Parameters listed for Molecule $A$ are idealized values included in structure factor calculations and refinements at 0.60 occupancy.

dTe occupancy parameter for this atom in molecule $B$ is estimated to be 0.2 .

'Parameters listed for Molecule $A$ are idealized values included in structure factor calculations and refinements at 0.4 occupancy.

the ureido carbonyl bond, $\mathrm{C}^{\prime}=\mathrm{O} 2^{\prime}$, and the double bond character of the $\mathrm{C}-\mathrm{N}$ single bonds, $\mathrm{C}^{\prime}-\mathrm{N} 1^{\prime}$ and $\mathrm{C}^{\prime}-\mathrm{N} 3^{\prime}$. These features were interpreted to arise from contributions of polarized forms of the biotin resomers and we described the carbonyl bond as being polarized and with enolate character. Some of the effects of the addition of the methoxycarbonyl group at $\mathrm{N} 1^{\prime}$ are catalogued in TABLE 3. The carbonyl, $\mathrm{C}^{\prime}=\mathrm{O} 2^{\prime}$ and the $\mathrm{C}_{2}^{\prime}-\mathrm{N} 1^{\prime}$ bonds are, respectively, shorter and longer than those observed in the uncarboxylated coenzyme, indicating decreased contributions from polarized resonance forms with less enolate (more keto) character in the carbonyl bond. The $\mathrm{C}^{\prime}-\mathrm{N} 3$ ' bonds retain their double bond character in the carboxybiotin derivatives.

The $\mathrm{N}^{\prime}$ methoxycarbonyl group lies in the plane of the ureido ring system but, in the present structure, the orientation of this group, relative to that observed in the methyl ester ${ }^{28}$ is flipped by $180^{\circ}$ about the $\mathrm{Nl}^{\prime}-\mathrm{C}_{\text {methoxy }}$ bond. The $\mathrm{N} 1^{\prime}-\mathrm{C}_{\text {methoxycarbonyl }}$ bond has approximately the equivalent single bond character as the $\mathrm{C}^{\prime}-\mathrm{N} \mathrm{l}^{\prime}$ bond 


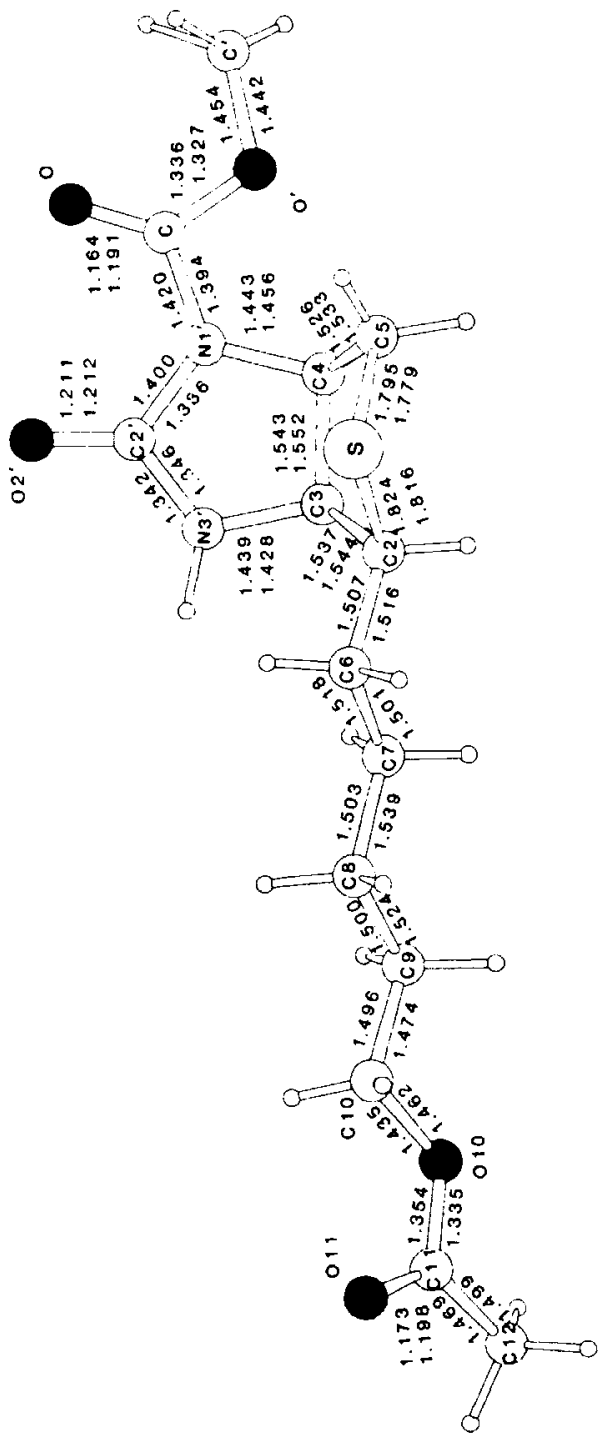

旁

的 논

늑 음

을

包

苋

寻落

$8 \dot{\text { ง }}$

얼 덜

픈

屿

$<$

늘 꼰

응

$\Sigma \underline{5}$

느므

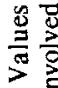

氙

要

至

흔

辰

등 군

ते

这

$\bar{z}$

흔

马

हू

巳

os

纹

范品

든을

롱.

品

ㄷㅇㅇㅇㅇㅇ

됮

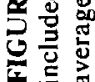


and, the valence angles about $\mathrm{N} 1^{\prime}$ sum to $360^{\circ}$, indicating the trigonal nature of this nitrogen atom. We attribute the observed electronic rearrangement in the ureido $\mathrm{C}^{\prime}=\mathrm{O} 2^{\prime}$ and $\mathrm{C}^{\prime}-\mathrm{N} 1^{\prime}$ bonds to the addition of the methoxycarbonyl group to the ureido ring; this addition allows the $p_{z}$ lone pair of electrons on $\mathrm{Nl}^{\prime}$ to overlap not only with $\mathrm{C}^{\prime}$, but also with the $\mathrm{sp}^{2}$ hybridized carbon atom of the methoxycarbonyl substituent. Hence much of the $\mathrm{C}^{\prime}-\mathrm{Nl}^{\prime}$ double bond character is displaced to the $\mathrm{NI}-\mathrm{C}_{\text {methoxycarbonyl }}$ bond; accordingly, the double bond (keto) character of the carbonyl bond is correspondingly enhanced as the $\mathrm{C} 2^{\prime} p_{z}$ orbital is able to become more intimately involved in overlap with $\mathrm{O} 2^{\prime}$.

The conformations of the side chains are illustrated in FIGURE 5. Starting from the sulfur atom, $\mathrm{C} 6-\mathrm{C} 9$ adopt all-trans zig-zag conformations and thereby resemble the conformations observed in aza-, oxy-, and carbobiotin as well as in biotin sulfone. ${ }^{9}$ At C9 the conformations of the two independent molecules differ from each other and are not chemically comparable to other biotin derivatives for which structures exist; in molecule $\mathbf{A}$, the acetate group almost continues the full extension of the side chain while the side chain of molecule B, for which we have detected disorder in the positions of $\mathrm{C} 9, \mathrm{C} 10$ and $\mathrm{O} 10$ (see above), terminates with two differently twisted, conformations. The side chain conformations differ strikingly from those observed for $\mathrm{N} 1^{\prime}$

TABLE 3. N1' Substituent Effects in Carboxybiotin Derivatives

\begin{tabular}{|c|c|c|c|}
\hline Bond & Biotin ${ }^{a}$ & $\begin{array}{l}\text { N1' Methoxycarbonyl } \\
\text { Biotinyl Acetate }\end{array}$ & $\begin{array}{l}\text { N1'Methoxycarbonyl } \\
\text { Biotin Methyl Ester }\end{array}$ \\
\hline$C 2^{\prime}=02^{\prime}$ & $1.249 \AA$ & $1.211 \AA$ & $1.206 \AA$ \\
\hline $\mathrm{C} 2^{\prime}-\mathrm{N} 1^{\prime}$ & 1.332 & 1.393 & 1.404 \\
\hline $\mathrm{C}^{\prime}-\mathrm{N} 3^{\prime}$ & 1.351 & 1.344 & 1.345 \\
\hline $\mathrm{N} 1^{\prime}-\mathrm{C}_{\text {methoxycarbonyl }}$ & - & 1.407 & 1.391 \\
\hline $\mathrm{N}^{\prime}-\mathrm{C4} 4$ & 1.459 & 1.449 & 1.457 \\
\hline
\end{tabular}

${ }^{a}$ DeTitta et al. ${ }^{6}$

${ }^{b}$ Average values from this study.

'Stallings et al. ${ }^{28}$

methoxycarbonyl biotin methyl ester ${ }^{28}$ for which the S-C2--C6--C7 conformations are -gauche.

One of the reasons for undertaking this structure determination was its potential for allowing us to visualize an interaction between the ureido moiety and the substrate-like $\alpha$-methyl carbonyl group located at the terminus of the side chain. Regrettably, no such interaction occurs in the packing of this crystal structure; instead, the molecules are held together as hydrogen-bonded dimers with N3'- $-\mathrm{H}$ and O2' of one molecule serving as donor and acceptor, respectively, in complementary hydrogen bonds to $\mathrm{O}^{\prime}$ and $\mathrm{N}^{\prime}-\mathrm{H}$ in another molecule.

\section{Re-examination of the Structure of N1' Methoxycarbonyl Biotin Methyl Ester}

In an earlier description ${ }^{28}$ of the packing observed in this structure we reported an intermolecular interaction between the ureido oxygen and a neighboring methyl group which we believed to be facilitated by the depolarization of the ureido carbonyl bond on addition of the $\mathrm{Nl}^{\prime}$ methoxycarbonyl group. In this interaction, the ureido oxygen, $\mathrm{O} 2^{\prime}$, is nestled in a cavity formed by the methyl hydrogens $\left(\mathrm{O}^{\prime} \cdots \mathrm{C}_{\text {methyl }}=3.1 \AA\right)$ 

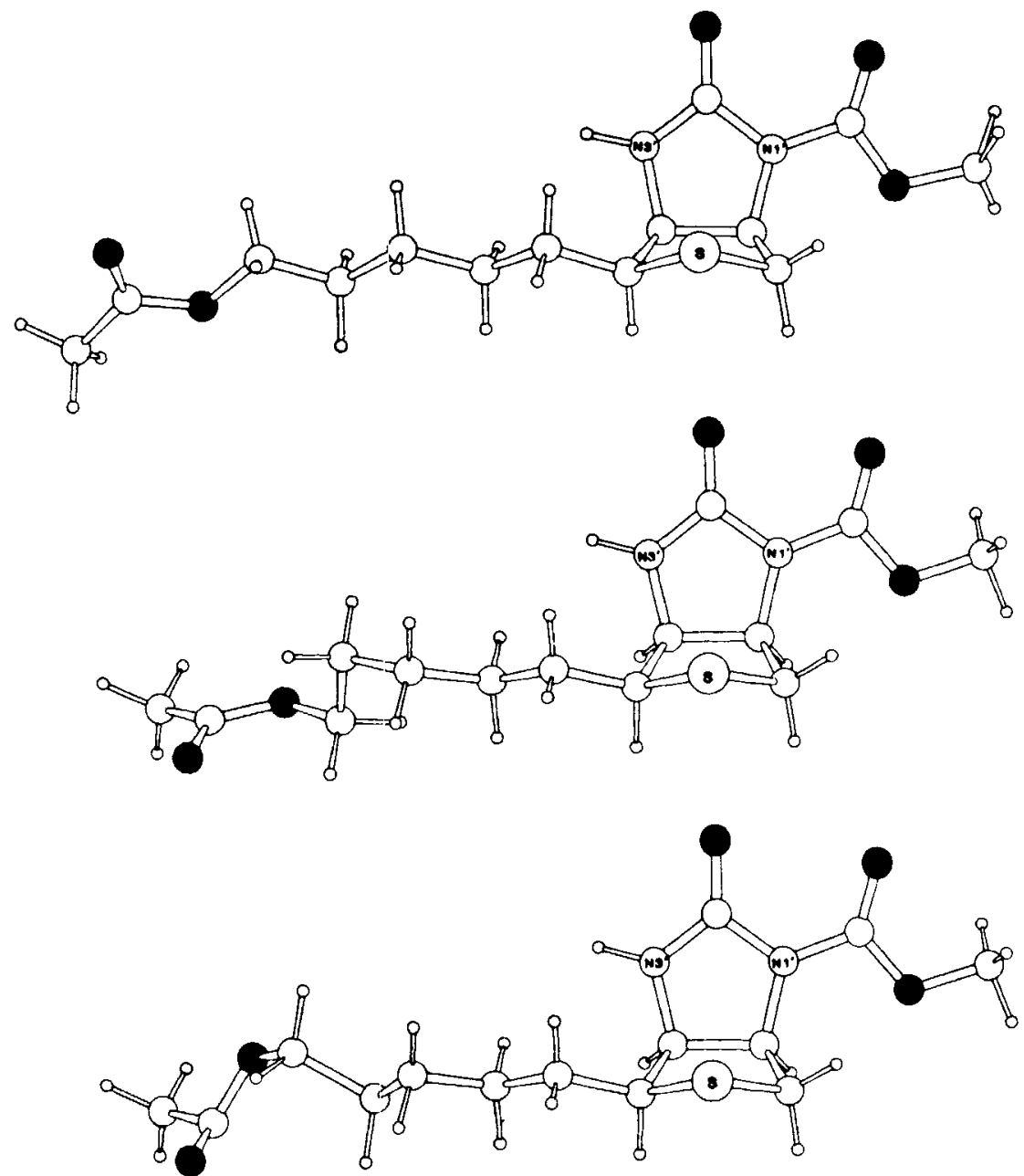

FIGURE 5. Conformations observed for $\mathrm{NI}^{\prime}$ methoxycarbonyl biotinyl acetate. (Upper) Molecule A. (Middle) Molecule B, higher occupancy conformation. (Lower) Molecule B, lower occupancy conformation.

and the interaction was described as asymmetric, occurring in the plane of the ureido ring but on the N1' side of the molecule as illustrated in FIGURE 6. Since our report of that structure, we have used computer graphics to analyze the van der Waals radii involved in this interaction. The disposition of the two methyl hydrogens which lie above and below the ureido ring (the third is to the left of these in FIG. 6a and lies in the plane of the ureido ring) is such that rotation of the methyl group is precluded; a rotational lock is imposed about the threefold axis of the methyl group in this interaction as the rotation would require that one of the methyl hydrogens bump (pass through space occupied by) the oxygen of the $\mathrm{Nl}^{\prime}$ methoxycarbonyl group which is 
a
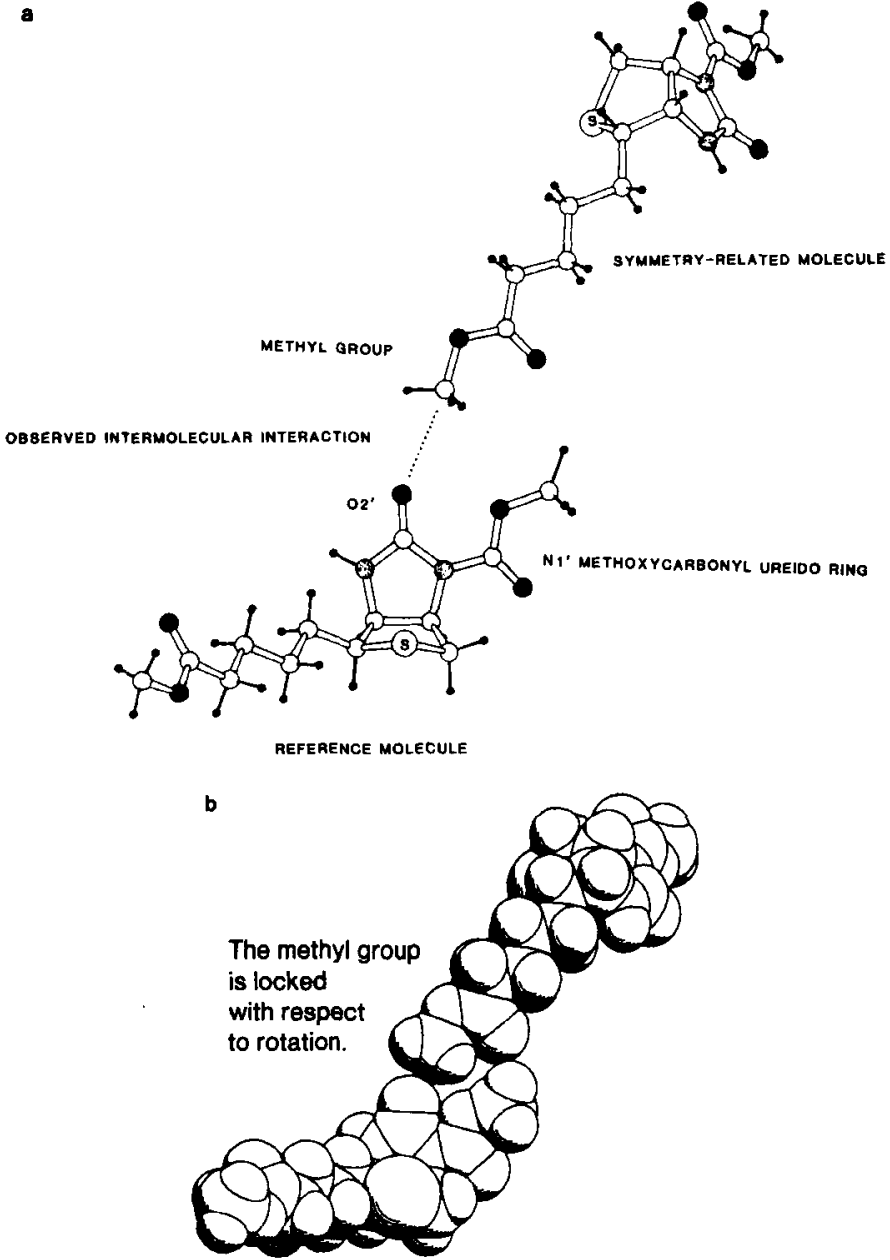

FIGURE 6. (a) Intermolecular interaction observed in the structure of $\mathrm{N}^{\prime}$ methoxycarbonyl biotin methyl ester. The ureido oxygen, $\mathrm{O}^{2}$, of one molecule is $3.1 \AA$ from the methyl carbon at the terminus of the methyl esterified valeryl side chain of a symmetry-related molecule. This is a van der Waals interaction in which $\mathrm{O2}^{\prime}$ is nestled among the methyl hydrogens. (b) The nature of this interaction is better visualized by a space-filling model in which a van der Waals radius is assigned to each atom. Note that the van der Waals contacts lock the methyl group with respect to rotation about its threefold axis since the rotation will cause the methyl hydrogens to bump the oxygen of the $\mathrm{N} \mathrm{I}^{\prime}$ methoxycarbonyl group proximal to $\mathrm{O2}^{\prime}$. The rotational lock can provide a structural basis for the stereospecificity observed in the second half-reaction. 
proximal to O2'. Although this is not evident in Figure 6a, it becomes clear in Figure $6 \mathrm{~b}$, which is a space filling model of the interaction.

The stereochemistry of the carboxyl-transferring reaction of the enzymes propionyl and acetyl $\mathrm{CoA}$ carboxylases, pyruvate carboxylase and transcarboxylase has been investigated $^{19-23}$ with labeled substrates and shown to proceed with retention of configuration at the $\alpha$-carbon. Such data, as well as failure to demonstrate exchange of the substrate proton with solvent in the absence of carboxybiotin, ${ }^{29}$ have been used in arguments favoring a concerted mechanism over a stepwise one; in the concerted mechanism abstraction of the $\alpha$-proton is concomitant with the addition of the carboxyl group. Rose and coworkers ${ }^{25}$ have further investigated the transcarboxylase reaction and demonstrated tritium transfer between the substrates, pyruvate, and propionyl-CoA; their results, considered with other data, lead them to suggest that the proton transferring agent is enol-biotin and that, in line with previously suggested mechanisms, ${ }^{19}$ carboxybiotin itself is the base that abstracts the $\alpha$-proton from substrate.

Our structural results can be interpreted in light of this information. The depolarization of the ureido carbionyl bond, observed in both $\mathrm{Nl}^{\prime}$ methoxycarbonyl derivatives, may serve to facilitate the non-polar interactions required in the second half-reaction by the acyl-CoA and pyruvate substrates. As described, we have observed such an interaction between the ureido oxygen and a methyl group. Close examination of the van der Waals contacts involved in this unusual interaction reveals that the interaction effectively immobilizes the methyl group with respect to rotation. If this interaction is mimicking the binding of substrate at the active site of a biotin enzyme, the rotational lock provides a structural basis for the stereospecificity observed in the carboxyl group-transferring reaction of biotin-mediated catalysis.

\section{SUMMARY}

The structures of a family of biotin and carboxybiotin derivatives have provided information on the mechanism of biotin action. The ureido moiety of the uncarboxylated cofactor is polarized and able to interact with ions and polar molecules; intermolecular interactions in the biotin derivatives suggest biochemical mechanisms resulting in nucleophilic activation to the enol tautomer.

$\mathrm{Nl}$ 'carboxylation of biotin is important not only as a chemical reaction to generate the carboxyl-transferring species, carboxybiotin, but also in acting as a switch to depolarize the ureido carbonyl oxygen, and thereby facilitating interactions with non-polar molecules. The structure of an N1' methoxycarbonyl biotin derivative reveals such an interaction between the carbonyl oxygen, $\mathrm{O}^{\prime}$, and a neighboring methyl group. A computer-generated space-filling model of the van der Waals contacts involved in this interaction reveals that the methyl group is locked with respect to rotation and thus suggests a structural basis for the stereospecificity observed in the carboxyl-transferring half-reaction.

The flexibility of the valeryl side chains in this family of structures provides translocation models in line with magnetic resonance data which indicate that the translocation events involve motions of, at most, $7 \AA$. Our models demonstrate that such motions may be accomplished by simple, observed conformational changes in bonds of the valeryl side chain which locally adjoin the bicyclic ring system.

High resolution, low temperature diffraction data will allow visualization of the bonding and lone pair electrons in biotin. These studies will serve to extend and 
fine-tune our description of the electronic structure of biotin which is currently based on accurate measurements of bond distances and angles.

\section{ACKNOWLEDGMENTS}

We are proud to contribute this paper in honor of Professor Harland Wood and his work. We gratefully acknowledge discussions with J. P. Glusker, H. L. Carrell, J. Donohue, A. S. Mildvan, M. D. Lane, R. Parathasarathy, and R. H. Blessing over the years. N1' methoxycarbonyl biotinyl acetate was a generous gift from the laboratory of Professor M. D. Lane. We thank D. Rapley for assistance in the preparation of this manuscript.

\section{REFERENCES}

1. du Vigneaud, V., K. Hofmann, D. B. Melville \& P. Gyorgy. 1941. J. Biol. Chem. 140: 643-651.

2. FANKUChEN, I. 1942. J. Am. Chem. Soc. 64: 1742-1743.

3. Traub, W. 1956. Nature 178: 649-650.

4. Bonnemere, C., J. A. Hamilton, L. K. Steinrauf \& J. Knappe. 1965. Biochemistry 4: $240-245$.

5. TROTtER, J. \& J. A. HAMILTON. 1966. Biochemistry 5: 713-714.

6. DeTitta, G., J. W. Edmonds, W. Stallings \& J. Donohue. 1976. J. Am. Chem. Soc. 98: $1920-1926$.

7. Stallings, W. C. 1977. Arch. Biochem. Biophys. 183: 189-199.

8. Pauling, L. 1960. The Nature of the Chemical Bond. Cornell University Press. Ithaca, NY.

9. Chen, C. S., R. Parthasarathy \& G. T. DeTitta. 1976. J. Am. Chem. Soc. 98: 49834990.

10. Glick, M. D., H. C. Wormser \& H. N. Abramson. 1977. Acta Crystallogr. B33: 10951101.

11. DeTitta, G. T., R. Parthasarathy, R. H. Blessing \& W. Stallings. 1980. Proc. Natl. Acad. Sci. USA 77: 333-337.

12. Blessing, R. H. 1983. J. Am. Chem. Soc. 105: 2776-2783.

13. Harkema, S., J. W. Bats, A. M. Weyenberg \& D. Feil. 1972. Acta Crystallogr. B28: $1646-1648$.

14. Kostansek, E. C. \& W. R. Busing. 1972. Acta Crystallogr. B28: 2454-2459.

15. Fung, C. H., A. S. Mildvan \& J. S. Leigh. 1974. Biochemistry 13: 1160-1169.

16. Fung, C. H., R. J. Feldman \& A.S. Mildvan. 1976. Biochemistry 15: 75-84.

17. Fung, C. H., R. K. GuPTa \& A. S. Mildvan. 1976. Biochemistry 15: 85-92.

18. IKURA, M. \& K. HIKICHI. 1982. Org. Magn. Reson. 20: 166-273.

19. RETEY, J. \& F. LYNEN. 1965. Biochem. Z. 342: 256-271.

20. Prescott, D. J. \& J. L. Rabinowitz. 1968. J. Biol. Chem. 243: 1551-1557.

21. Rose, I. A. 1970. J. Biol. Chem. 245: 6052-6056.

22. Chung, Y. F., C. H. Fung \& C. WaLSh. 1975. Biochemistry 14: 2981-2986.

23. Sedgwick, B., J. W. Cornforth, S. J. French, E. Kelstrap \& R. Willadsen. 1977. Eur. J. Biochem. 75: 481-495.

24. KUO, D. J. \& I. A. Rose. 1982. J. Am. Chem. Soc. 104: 3235-3236.

25. Rose, I. A., E. L. O'CoNnell \& F. SOlomon. 1976. J. Biol. Chem. 251: 902-904.

26. Stubbe, J. \& R. H. Abeles. 1977. J. Biol. Chem. 252: 8338-8340.

27. Stubbe, J., S. Fish \& R. H. Abeles. 1980. J. Biol. Chem. 255: 236-242.

28. Stallings, W. C., C. T. Monti, M. D. Lane \& G. T. DeTitta. 1980. Proc. Natl. Acad. Sci. USA 77: $1260-1264$.

29. Mildvan, A. S., M. C. SCrutton \& M. F. Utter. 1966. J. Biol. Chem. 241: 3488-3498. 


\section{DISCUSSION OF THE PAPER}

A. S. Mildvan (Johns Hopkins University School of Medicine, Baltimore, MD 21205): If there is a carbanion intermediate it is much easier to immobilize it than to immobilize rotation of a methyl group.

W. Stallings: Yes, but in any case you will want to initially immobilize the methyl group.

MildVAN: First, let me say that we attempted to explain the kinetic difference that we consistently observed between $\mathrm{N}-1$ and $\mathrm{N}-3$, a much more rapid proton exchange at $\mathrm{N}-1$ than at $\mathrm{N}-3$ in terms of a steric effect at N-3. My question is, with your very careful bond length measurements and with this more recent electron density observation do you see any electronic difference at N-1 and N-3 of biotin which could provide an alternative explanation for this obvious kinetic difference?

STALLINGS: No, as a matter of fact we saw in our moderate resolution structure which I mostly talked about, that the $\mathrm{C}^{\prime}-\mathrm{N} 1^{\prime}$ and $\mathrm{C}^{\prime}-\mathrm{N}^{\prime}$ were just barely significantly different. In George's high resolution refinement he has seen that they are essentially the same. So the answer is no.

G. DETITTA: But I will comment that in the high resolution structure the NH hydrogen on $\mathrm{Nl}^{\prime}$ is actually out of the plane of the ureido ring more than the $\mathrm{N} 3^{\prime}$ hydrogen. And it is flipped to the back opposite to the side of the sulfur.

MILDVAN: That would make it a little more acidic wouldn't it?

DeTitTa: Yes. 